\title{
"Divagación": la geografía erótica de Rubén Darío
}

QI el poeta Pedro Salinas tiene razón cuando dice que "en Azul y D Prosas profanas lo amoroso predomina sin disputa" y que "de las treinta y seis poesías que contiene el índice de Prosas profanas, no hay más de cuatro o cinco que se aparten de ese obsesivo asunto", 1 entonces no nos debemos sorprender que en "Era un aire suave", el primer poema de Prosas profanas, Darío evoque un dulce mundo de exquisitos flirteos y anuncie lo que serán esos himnos eróticos en que Eros saltará de una página a otra. Sin duda, buena parte de la inspiración de ese primer poema proviene de Paul Verlaine. $Y$ aunque Rubén no nombre a todos sus personajes, se sabe que "ese vizconde rubio de los desafíos" y "el abate joven de los madrigales" ya existían en la obra del pobre Lelián:

\section{L'Abbé confesse bas Eglé}

et ce vicomte déréglé

Des champs donne à sen coeur la clé. ${ }^{2}$

Vuelven a aparecer en "Divagación" estos mismos personajes ("Los abates refieren aventuras/a las rubias marquesas...") y allí en el segundo poema se repiten algunas de las amorosas ligerezas y también la invitación al amor. Sin embargo, en "Divagación" ya no se trata de un baile de máscaras en que al compás de la música de Rameau y de Lully unos "duques pastores" juegan al amor. Ahora Darío cambia rápidamente de escenario al pasar de país en país dictando su breve curso de geografía erótica. Pero, en realidad, Rubén nos proporciona muy pocos detalles

1 Pedro Salinas, La poesía de Rubén Dario, 2a. edición. (Buenos Aires, 1957), p. 55.

Paul Verlaine, Oeuvres poétiques complètes (Paris, 1962) p. $108 \mathrm{cf}$. Ar. tự Marașso, Rubén Dario y su creación poética (Buenos Aires, 1954), p. 40, 
sobre el amor en países exóticos; y no se debe criticar severamente al lector que se sienta algo defraudado al terminar la lectura del poema. En verdad que "Divagación" nos puede desconcertar con su tono de frivolidad y con sus múltiples manifestaciones de un amor cosmopolita.

En su comentario al poema, José Enrique Rodó señala la semejanza entre "Era un aire suave" y "Divagación", sosteniendo que la mujer de "Divagación" realmente "sigue siendo siempre una francesa del siglo de 'los duques-pastores', una joven marquesa, una nieta mimada de Marivaux, como aquella deliciosa Eulalia que aparece escapada de una página de los 'Juegos del amor y el azar' o de las 'Falsas confidencias' " 3 Rodó afirma que mucho más notable en el poema son "todas las exquisiteces del decir" y "todas las graciosas petulancias de las formas". ${ }^{4}$.Erwin Mapes, en L'Influence française dans l'oeuvre de Rubén Dario, llega a la conclusión de que Darío "est un artiste pur, et peu lui importe le sujet, pourvu qu'il lui offre une accasion de développer ses merveilleux dons techniques". ${ }^{5}$ Y Valbuena Prat cree ver en la poesía "Divagación" "una clara definición de los motivos exteriores del modernismo". 6 Hay que reconocer que Darío se hizo cómplice de la creación del mito de un Rubén "artiste pur", del poeta preocupado sobre todo por las "exquisiteces del decir". Sabemos que el poeta nicatagiiense elogia sin reservas el estudio de Rodó y hasta declara que considera el trabajo del uruguayo "completo", "magistral y célebre opúsculo".7 También dice que de las poesías de Prosas profanas, "ha hecho el autor de Motivos de Proteo una encantadora exégesis". 8 Y en su comentario a "Divagación" casi nos convence de la frivolidad de su poema: ". . . hay una sed amorosa, y en la manifestación de los deseos y' en la invitación a la pasión se hace algo como una especie de geografía erótica". ${ }^{9}$ ¿No tendremos que culpar —en parte, por lo menos-al propio Rubén por el hecho de que "llegó a calificársele de artífice desprovisto de ideas, privado de toda filosofía y carente de dogmas éticos" ?10 Recientemente, por ejemplo, se nos ha querido hacer creer que en "Divagación" nuestro poeta "canta un amor voluble, veletero, mariposeante, sin raíz y sin comprensión para más que

3 José Enrique Rodó, Hombres de América (Montevideo, 1944), pp. 252-253.

4 Ibid., p. 253.

5 Erwin K. Mapes, L'Influence française dans l'oeuvre de Rubén Dario (París, 1925), p. 139.

16 Angel Valbuena Prat, Histaria de la literatura española (Barcelona, 1950), III, 375 .

7 Rubén Dario, Obras completas (Madrid, 1950-1953), I, 204.

8 Ibid., I, p. 118.

9 Ibid., p. 119.

10 Jaime Torres Bodet, "Perennidad de Rubén Dario", Revista de la Univer. sidqud de México ('Septiembre, 1966), p. 2. 
la flor de la piel" y' que no obstante "todo esto admisible o vituperable" el poema "está resuelto en encendida poesía de gloria musical, garbo deleitoso de ritmo, cabrilleo inédito de imágenes, tersura juvenil, que le absuelve de frivolidad". II Afortunadamente, otros han considerado a Darío más que artífice de la palabra. Arturo Marasso nos asegura que en "Darío hay también un poeta hermético. Muchos de sus versos se esconden a la interpretación más sutil; generaciones de eruditos desentrañarán su sentido...".12 Años atrás, uno de los mejores amigos de Rubén, Ramón del Valle-Inclán, se quejaba de que la poesía del nicaragüiense no se entendiera ni se apreciara debidamente. En una carta a Darío, Valle-Inclán recomendaba al Cónsul General de Francia en España, M. Chaumié, "que sabe buscar hasta el fondo esotético de los versos de usted, que tan arcanos se le presentan a tantos de nuestros académicos, críticos y poetas". 13

Pero ¿qué tienen que ver estos juicios tan diversos con "Divagación"? ¿Podremos aceptar que este poema es hermoso en su forma pero esencialmente carente de ideas? ¿O tendrán esos versos voluptuosos un fondo menos insustancial?

\section{I}

"Vienes?", escribe Darío, y el poeta Pedro Salinas no se equivoca al pensar que Rubén se dirige a la amada invitándola a acompañarlo en un viaje de amor. ${ }^{14}$.Esta primera palabra refleja probablemente algunas lecturas de Rubén. Recuérdese que uno de los poetas predilectos de Darío, Théodore de Banville, empieza uno de sus poemas, "Viens. Sur tes cheveux noirs jette un chapeau de paille", 15 y parece que este recurso estilístico se encuentra también en Les trophées de Heredia: "Viens. Le sentier s'enfonce aux georges du Cyllene". ${ }^{16}$ Pero más que probable es que Rubén conociera el poema "Bacchus" de André Chénier: "Viens, o divin Bacchus, o jeune Thyonée/o Dionyse...".17 Rubén había escrito: "...comprendí que no sólo el galicismo oportuno, sino ciertas particu-

II Ramón de Garciasol, Lección de Rubén Dario (Madrid, 1961), p. 144.

I2 Arturo Marasso, Rubén Dario y su creación poética, pp. 5-6. p. 419.

I3 En Alberto Ghiraldo, El archivo de Rubén Dario (Burenos Aires, 1943),

14 Op. cit., p. 128.

15 Thêodore de Banville, Les stalactites, (París, 1942), p. 158.

16 Del soneto "Les bergets", Les tropbées, ed. bilingüe (Filadelfia, 1962), p. 22.

17 André Chénier, Oewvres poétiques, (París, 1925), I, 107. 
laridades de otros idiomas, son utilísimos y de una comparable eficacia en un apropiado trasplante". ${ }^{18}$ ¿Será el "Vienes?" de Darío uno de esos "apropiados trasplantes"? Obsérvese que en francés "Viens" es imperativo y Rubén dice "Vienes?", agregando el punto de interrogación. ¿Por qué no escribe Darío "Ven"? Góngora, dentro de la tradición clásica de los epitalamios - pensamos en Catulo- dice: "Ven, Himeneo, ven donde te espera/con ojos y sin alas un Cupido". ${ }^{19} \mathrm{El}$ trasplante de Darío. nos parece mucho más apropiado porque con una invitación galante concuerda mejor una grata pregunta que un brusco mandato.

¿Sabemos a quién va dirigida la pregunta? "La invitada es simplemente la pareja, la figurante que necesita para representar el dúo de amor itinerante que se inicia", ${ }^{20}$ dice Pedro Salinas. ¿Se tratará simplemente de la pareja o pensaba Rubén específicamente en alguien? Nuestro poeta cuenta: 'Mi poesía 'Divagación' fue escrita en horas de soledad y de aislamiento que fui a pasar en el Tigre Hotel. ¿Tenía yo algunos amoríos? No lo sabré decir ahora". ${ }^{21}$ La pocsía, como señala Marasso, es "Ronsardista", ${ }^{22}$ es decir, pertenece a la tradición de "Mignonne, allons voir si la rose..." y del "Sonnet pour Hélène"; es evidente que también refleja algo de "L'Invitation au voyage": "Mon enfant, ma soeur,/ Songe à la douceur/D'aller là-bas vivre ensemble!'. Pero aunque Rubén tenga presente, muy presente, los deliciosos versos de Ronsard y el exquisito exotismo de Baudelaire ('La, tout n'est qu'ordre et beauté,/Luxe, calme et volupté."), en este poema, el joven nicaragïense sigue de cerca el arquetipo mitológico:

\section{Suspiras así! Revuelan las abejas al olor de la olimpica ambrosín, en los perfumes que en el aire dejas;}

No hay duda de que se trata de Venus. Es ella la de la ambrosía y la de las abejas. Ya ha notado Arturo Marasso que en La Eneida (I, 403) se habla "del aroma que esparce la cabellera de Venus". Es pues a la eterna Venus a quien Rubén invita a recorrer continentes y a "pasar revista a las 'estampas' de diversas culturas y civilizaciones". ${ }^{23}$

18 Obras completas, I, 196.

19 En Biblioteca de Autores Españoles (Madrid, 1950), XXXII, 468.

20 Op. cit., p. 128.

21 Obras completas, I, 118.

$\$ 2$ op. cit. $\mathrm{g}, 43$.

as Ibid, p. 44 . 
Al explorar el universo de amor, ¿se acuerda Rubén del Ars amandi o de alguna otra obra de Ovidio? De que conociera la obra de Ovidio nadie podrá dudar puesto que en la epístola "A Ricardo Contreras" menciona en la novena estrofa a "Publio Ovidio Nasón (q. e. p. d.)"24 y se sabe que Darío había tenido a su disposición las traducciones de autores clásicos que se habían publicado en la Biblioteca Clásica de Madrid. ${ }^{25}$ En los Amores de Ovidio entonces pudo haber leído unos versos que nos recuerdan las mujeres de diferentes razas que se encuentran en "Divagación": "candida me capiet, capiet me flava puella,/est etiam fusco grata colore Venus". (II, 4).

Igualmente posible es que Rubén estuviera pensando en la obra $D e$ $\checkmark$ amour de Stendhal. Hay que recordar que en ese tratado el novelista francés describe el amor en países tan diversos como Inglaterra, España, Italia, Francia, etc. Sin embargo, acaso esta vez Rubén recordara un poema de Théophile Gautier. En "Barcarolle", uno de tantos viajes poéticos a Citeres, Gautier le pregunta a una joven, "Dites, la jeune belle, JOù voulez-vous aller". ${ }^{26}$ Luego:
Est-ce dans la Baltique,
Sur la mer Pacifique,
Dans l'île de Java?
Ou bien dans la Norvège, Cueillir la fleur de Neige,
Ou la fleur d'Angsoka?

La joven contesta que quiere ir al lugar donde siempre se ama, "a la rive fidèle", y se le responde que "On ne la connaît guère/Au pays des amours". Se sabe que al escribir "Divagación" Darío pensaba en Gautier puesto que incorpora en el texto de su poema el verso: "Gautier adoraba a las princesas chinas". $Y$ es en "Chinoiserie" de Gautier donde leemos:

Ce n'est pas vous, non, madame, que j'aime,
Ni vous non plus, Juliette, ni vous,
Ophélia, ni Béatrix, ni même
Laure la blonde, avec ses grands yeux doux. 27

24 Rubén dice de Ovidio: "En ese Ars amandi os sonríen variadas y gracio. sas ideas femeninas. Provocan, llaman a la batalla de amor..." Obras completas, I, 457.

25 Errnesto Mejía Sánchez, "Las humanidades de Rubén Dario" en Libro ju" billar de Alforso Reyes (México, 1956), pp. 252-263.

26 Théophile Gautiert, Ematux et Camées (Paris, 1954), p. 238.

at thid., p. 240. 
Claro que aquí no se representan diversas nacionalidades pero sí diferentes tipos de mujeres -ideales femeninos europeos sacados de la literatura. Pero nótese que Gautier se declara enamorado de una china: "Celle que j'aime, à présent, est en Chine;/Elle demeure avec ses vieux parents,/ Dans une tour de porcelaine fine...". ${ }^{28} \mathrm{El}$ poeta francés proclama que su novia oriental posee "Le teint plus clair que le cuivre des lampes..." y continuando en el soneto que sigue, Gautier asegura que

La blanche porcelaine est d'un blanc bien moins pur

Que son col transparent et ses tempes d'agates...29

Desde luego, Gautier no es ni el primero ni el único que haya equiparado el cutis de su amada a la porcelana. Pero si a Gautier le parece la porcelana menos blanca que su amada de China, Darío juzga que el mismo cielo es menos rico y admirable que la hermosa amante de "mil genuflexiones" y de "pies imposibles":

Diré que etes más bella que la luna; que el tesoro del cielo es menos rico que el tesoro que vela la importuna caricia de marfil de tu abanico.

Obsérvese que el exótico preciosismo de Gautier se hace más general en Darío y que ahora ya no se compara la blancura de la amada sino "el tesoro del cielo" a la exquisita perfección de la amada. Si se acepta la posibilidad de influencia - o por lo menos, de coincidencia- no se debe concluir por ello que todo el poema de Darío no constituye más que una simple imitación de Gautier. ¿Por qué tendría Darío que seguir un modelo francés para imaginarse amores en tierras exóticas? El poeta de Metapa había viajado y vivido en varios países americanos y europeos; bien podría inspirarse en sus propias experiencias amorosas. ¿No es él un moderno Ulises del Nuevo Mundo que también deja a su Penélope y Telémaco en su Itaca centroamericana? Sin embargo, consta que en "Divagación" Rubén no se limita a los países que conoce; por el contrario, nombra en el poema tierras que jamás conoció. ¿Se encontrará en "Divagación" alguna alusión a la mujer americana? Ni la centroamericana, ni la argentina, ni la chilena se asoman en esas "estampas". Parece que Rubén excluye preccişamente la mujer y los países que conocía mejor. 
¿Será que Darío escribió su poema muy de prisa, improvisando "estampas" arbitrariamente? La primera lectura de "Divagación" nos puede dejar con semejante impresión. ¿Dónde se habrá visto viaje más extraño que éste? ¡Se principia en una Arcadia y se termina en unos palacios solitarios! Por otra parte, convenía que Rubén comenzara describiendo el mundo pagano. Con el bosque sagrado de bacantes y bacanales se evoca la antigüedad clásica, es decir, el amor primordial, lo eterno, lo universal del amor y justamente en sus manifestaciones artísticas. No se especifica si se está en Roma o en Grecia, ${ }^{30}$ y esto quizá porque Rubén acepta la unidad esencial del mundo clásico. En todo caso, se trata de una Arcadia bastante muerta en que los dioses paganos sólo viven en las obras de arte. En la segunda división de la poesía sobre las estrofas dedicadas a Europa, se percibe una visión versallesca de la Francia del siglo xvirr. Hay que reconocer que Darío procede por la ruta cronológica de las civilizaciones: si después de Grecia, fue Roma el centro de la civilización occidental, ahora Francia ocupa ese lugar. Y Darío no describe una Francia contemporánea sino la clásica, la versallesca de Luis XVI y de Watteau. Las civilizaciones antiguas han pasado a la historia; ahora la francesa es la que corresponde al hombre moderno: "Amo más que la Grecia de los griegos/la Grecia de la Francia...".

Se debe notar que si pasamos revista a las mujeres que aparecen en "Divagación", encontraremos que por lo menos en la primera mitad del poema se trata de figuras literarias. ¿Qué sería la literatura clásica sin Venus? Y la Marquesa Eulalia es simplemente una de las marquesas de las Fêtes galantes tanto de Verlaine como de 'Watteau. El anónimo amor florentino debe pertenecer a Boccaccio puesto que Darío dice que es "reina de los decamerones". Esta curiosa manera de recordar personajes literarios acaso equivalga en parte a las alusiones a Julieta, Ofelia, Beatriz y Laura en el ya citado poema de Gautier. Al mencionar la legendaria sirena Loreley y a Gretchen, célebre personaje de Goethe, nuestro poeta no hace más que seguir rememorando protagonistas de la literatura.

Curioso que al describir el amor en España, Rubén no se valga de la España que conocía sino de la España de pandereta. Le perdonamos esa Alemania libresca, pero ¿cómo justificar esa España de clavel y flor extraña "regada con la sangre de los toros", esa "flor de gitanas, flor que amor recela,/amor de sangre y luz, pasiones locas..."? Darío re-

30 En el poema se habla de Diana y de Adonis, y en la primera estrofa" se mencionan "las Grecias, las Romas..." Parece que Darío prefiere dejar esa escena ambigua aunque en la siguiente parte diga, "Te gusta amar en griego?" 
curre a lo que a muchos les parecerá una España espuria, la España de Mérimée, la de Gautier "que parecía en el periodo romántico como una península de cuento". ${ }^{31}$ ¿No creerá el poeta que mos ofrece una España falsa? Al contrario, dice en su ensayo sobre los toros: "Y comprendí el alma de la España que no perece, la España reina de vida, emperatriz del amor, de la alegría y de la crueldad...".32 No hay duda: Darío prefiere la España "byroniana, de Gautier, la de D'Amicis".

En cuanto a las estrofas sobre el Japón, se sabe que en el ensayo "Bajo las luces del sol naciente" ya había censurado los cañonazos que destruyeron la civilización sin par del Japón viejo. Allí también tecuerda lo que "revelaron los Goncourt' a la curiosidad y al arte occidentales", asimismo que todo lo que Lafcadio Hearn explica de la civilización japonesa. $^{33} \mathrm{Y}$ respecto a los otros episodios o escenas, se podrían agregar detalles sobre sus fuentes, pero ¿para qué seguir acumulando datos que sólo probarian lo que ya se sabe? Baste repetir que todas las mujeres de "Divagación" pertenecen de alguna manera a las lecturas de Rubén

También es evidente que las mujeres mencionadas - Venus, las marquesas, Clelia, Gretchen, Loreley, las gitanas, el amor hindú, las bellas orientales y la hermosa Sulamita- tienen como denominador común el amor pasional. La única figura de contraste - Diana- está aquí descubriendo su "muslo de marfil". ¿Paseo sentimental algo turístico? Si Rubén nos presenta versiones turísticas del amor en diversos países, no es porque no se dé cuenta de que en los toros y en las gitanas no se puede encerrar todo lo español. $Y$ sabe también que hay alemanas que no se parecen en nada a Loreley y a Gretchen. El caso es que Rubén busca lo extravagante, lo raro y singular, la voluptuosidad, la pasión; por eso acude a lo que le sugieren sus lecturas, a las interpretaciones literarias del amor. Ya —años antes- se había declarado enemigo de la época en que había nacido ("yo detesto la vida y el tiempo en que me tocó nacer") $; 34$ ciertamente hubiera preferido un mundo de fantasía, un mundo poblado por personajes literarios. ¿Será acaso porque creía encontrar en la literatura las esencias, síntesis de múltiples existencias? En Gretchen no se conserva solamente el recuerdo de una alemana seducida por Fausto sino la imagen arquetípica de la joven que se entrega a

31 Obras complezas, III, 139.

32 Ibid., 142.

33 Ibid., IV, 998-1007. Respecto a las estrofas sobre el Japón, hay que señalar que Rubén piensa también en una actriz: "En dónde está ese mundo de vagos ensueños, ese mundo como Iunas extraterrestres, como astral, que admiré en las escenas en la maravillosa actriz Sada Yacco, que era una revelación de belleza exótica y peregrina?" Ibid, p. 1006.

34 Ibid, V, 763 . 
la pasión. De la misma manera en cada Clelia y en cada marquesa se insinúa la eterna coqueta. En cambio, las gitanas y Loreley no inspiran una lubricidad sin terror - femmes fatales clásicas. Así cada amante se diferencia de la otra, y se progresa de la orgía pagana a la fiesta galante, del amor florentino estilo Boccaccio al apacible paseo por el Rhin en compañía de la desventurada Gretchen y la temible Loreley, ${ }^{35}$ terminándose el recorrido europeo con las pasiones ardientes de las gitanas españolas. La sensualidad exótica de las orientales nos conduce hacia el amor brahmánico para culminar en el extático amor del Cantar de los Cantares. Desenfrenada pasión, dulces flirteos, seductores pero peligrosos amores, y sublime amor místico: es pues un amor multiforme lo que busca Rubén en su extraordinaria serie de breves visiones eróticas.

Salinas cree que Darío fracasa en su intento de abarcar "la pasión de todos los colores y de todos los tiempos": "Así el ansia amorosa rubeniana pintándose a sí mismo esos dioramas para el idilio, se engañaba pensando que ha amado en todas las épocas y sobre todas las tierras del mundo", y se pregunta el poeta español: "A fuerza de ser tantas figuraciones, la francesa, la española, la india, etc., todas con sus atributos y trajes nacionales, comó una hilera de muñecas, ¿no se perderá la realidad de la mujer verdadera? Con tantos espejos donde las imágenes se devuelven, se reflejan, ¿no huirá la forma humana cierta, imposible de discernir, de apresar entre tantas apariencias fugitivas?".36 Pero Salinas supone que Rubén debería haber apresado "la forma humana cierta" y cree un defecto que haya tantas "apariencias fugitivas". ¿Por qué tendría Darío que apresar "la forma humana cierta"? Si las representaciones de las amantes permanecen superficiales es porque las apariencias por definición manifiestan sólo lo exterior. Con esa visión turística Rubén ha querido brindarnos la mujer en sus diversas "apariencias". El turista acaso no vea en el pueblo extranjero sino esos aspectos que le parecen más extraños, diferentes, y que cree no encontrar en su propia país. Esto es precisamente lo que nos comunica Rubén al describirnos el colorido exótico -apariencial - de las mujeres india, africana, griega, alemana, italiana, etc. El sabe que a pesar de la aparente diversidad - marquesas, princesas, campesinas, bailarinas - la mujer española no difiere propiamente de la china, ni la africana de la rusa, alemana o turca. Lo que se puede descubrir entre tantas engañosas figuraciones es precisamente lo eternamente femenino, la mujer esencial revelada en el amor.

35 Ya en "Por el Rhin", Darío se refiere a estos personajes. cf. Obras completas, IV, pp. 989-996. En "Los pescadores de sirenas" dice, "Péscame una que tenga verdes los cabellos, como debe tenerlos Lorelay". IV, 440-441.

36 Op. cit., p. 132-133. 


\section{III}

Rubén nos ha trasladado del continente europeo al asiático y, pasando por China, el Japón y la India, llegamos por fin a los palacios de Salomón. Luego, de repente, la mujer escondida detrás de todas las "apariencias" exóticas rompe sus finos cendales y emerge, desnuda y absoluta. El poeta, frenético, exclama:

\footnotetext{
Āmame, así, fatal, cosmopolita, universal, inmensa, única, sola y todas; misteriosa y erudita: ámame mar y nube, espuma y ola. ${ }^{37}$
}

No es de extrañar que esta estrofa haya suscitado tantos comentarios. Valbuena Prat ve "el vaho panteísta del fin del siglo, de las últimas esencias del sentimiento de la naturaleza en el xix". ${ }^{38}$ Y Arturo Marasso comenta: "Un único rostro donde se anima la naturaleza toda, lo eterno femenino del universo, en la elegida. ${ }^{39}$ Salinas, en lo fundamental, no disiente de esta interpretación: "lo femenino en función amante, rompe los moldes de la forma mujer, y se infunde en los mares y los cielos, en las espumas y las nubes...".40

En verdad que el último verso de la estrofa nos sorprende. Si se trata de la esencia de la mujer diluida en el cosmos, como se sugiere, no nos oponemos a que Rubén se refiera al mar, a las nubes y a la espuma. Pero ¿por qué no al fuego, a la tierra y al viento? ¿Por qué sería menos apropiado invocar el trueno y el relámpago, los cerros y las montañas? Si de veras se trata del eterno femenino, ¿por qué limitarse específicamente a la espuma, nube, ola y el mar?

37 Mejía Sánchez (op. cit., p. 249) cita a Osvaldo Bazil: Rubén Darío "leía la Biblia... En todos los países donde llegaba, Rubén adquiría un ejemplar de la Biblia. Exigía que fuera con el texto en latín con la traducción española al frente". Ahora, ¿será posible que haya un recuerdo de la Biblia en los versos que citamos? En Sirbiduria leemos:

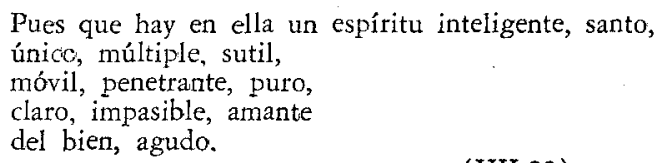

Hay que advertir que citamos por una traducción reciente:

Sagradid Biblia, Ed. Regina (Madrid, 1966).

38 Valbuena Prat, p. 375.

39 Marasso, p. 52.

40 Salinas, p. 134. 
Se sabe que una de las manifestaciones clásicas del eterno femenino, la diosa Venus, surge del mar, nace de la espuma, y una ola la lleva a Chipre donde se le rendirá culto como diosa del amor. Pero la nube, ¿Cómo viene a inmiscuirse en lo venusino? Rubén también debía saber que se acepta generalmente que Venus representa el elemento húmedo en la naturaleza. En la Grande Encyclopédie, leemos: "Aphrodite ellemême exprime le principe humide, cause de toute génération, de toute fécondité dans la nature".41 Además, Darío tuvo que detenerse algunos minutos para meditar lo que leyó en el poema "La nue" de Théophile Gautier:
A l'horizon monte une sue, Sculpant sa forme dans l'azur:
On dirait une vierge nue
Emergeant d'un lac au flot pur.
Debout dans sa conque nacrée, Elle vogue sur le bleu clair, Comme une Aphrodite éthérée, Faite de l'écume de l'air.42

El agua —ola, espuma, nube o mar- en efecto refleja a Venus, símbolo de la fecundidad, del principio mismo de la regeneración. Recuérdese que Tales de Mileto había dictaminado que el agua constituía el elemento primario, y que todo lo demás no era más que agua transformada. Más detalladamente en Philosophia secreta, Juan Pérez de Moya explica: “...ella [Venus] tiene parentesco con el mar, por cuanto del nació, en donde comienza: Áquila, et mibi gratid, etc., y por haber nacido así, los griegos la llamaron Afrodisa o Afrodite, de Aphros, que es espuma, o porque, según San Fulgencio, dice que se dijo así porque el humor o simiente viril imita a la espuma del mar...; tuvo tan ardiente el deseo sensual, que no sólo a algunos más a todos se dio...."43

Ese fogoso deseo sexual de Venus se ve reflejado en todas las escenas de "Divagación". Ya en "Era un aire suave" el poeta había ocultado a Venus detrás de la máscara y de la risa metálica de la Marquesa Eulalia, como lo nota Salinas; ahora Darío elabora el tema multiplicando las apariencias de Venus para poder forjarse su "geografía erótica". Venus anima toda la creación y Rubén escribirá más tarde de la mujer:

41 La grande encyclopédie, (Paris, s.f.), XXXI, 826

42 Gautier, p. 118.

43 Pbilosopbia secreta (Madrid, 1928), I, 33-34. 
"...en ella se respira/el perfume vital de toda cosa".44 ¿Por qué llamará al cuerpo femenino "celeste carne de mujer"? Por la misma razón que el nicaragïense apostrofa a Venus: ". . fatal, cosmopolita". Nosotros debemos vivir en armonía con los astros cumpliendo en el amor nuestro destino cosmológico. Si Gautier había dicho, "Mets dans ton coeur beaucoup de ciel,/Aime une nue, aime une femme,/Mais aime!. .", ${ }_{45}$ Darío aconsejará: "Amar, amar, amar, amar siempre, con todo/el ser y con la tierra y con el cielo,/con lo claro del sol y lo obscuro del lodo...".46

\section{IV}

Si es Venus la diosa que empuja a la mujer hacia el amor y si ella de veras se oculta en las amantes que encontramos en "Divagación" $i^{a}$ cuál de los dioses paganos le incumbe despertar el instinto sexual en el hombre y cuál de ellos se esconderá en los individuos nombrados en el poema? Aunque Venus no se mencione directamente, su presencia nos parece innegable. ¿Se podrá afirmar algo parecido con respecto a alguno de los dioses de la antigüedad? No se olvide que Rubén pide que

$$
\begin{aligned}
& \text { el dios de piedra se despierte y cante } \\
& \text { la gloria de los tirsos florecientes } \\
& \text { en el gesto ritual de la bacante } \\
& \text { de rojos labios y nevados dientes... }
\end{aligned}
$$

Según Arturo Marasso, "el dios de piedra" tiene que ser Dionysos, y, continúa el crítico argentino, "Darío, más plástico, tiene presente los triunfos de Baco" ${ }^{47}$ De este modo, en el poema "Pórtico" encontramos a "Venus en frente de un triunfo de Baco".48 No hay duda de que Darío consideraba completamente normal la pareja de Venus y Baco. En "La leyenda de San Martín" nos dice: "Nada para él de Dionisio, nada de Venus", ${ }^{49}$ indicando con esto que San Martín permaneció casto.

Pero en "Divagación", además de la escena en que se mienta al dios de piedra, ¿se acuerda Rubén de Baco? Curioso es que Arturo Marasso, viéndose obligado a explicar por qué el nicaragüense menciona

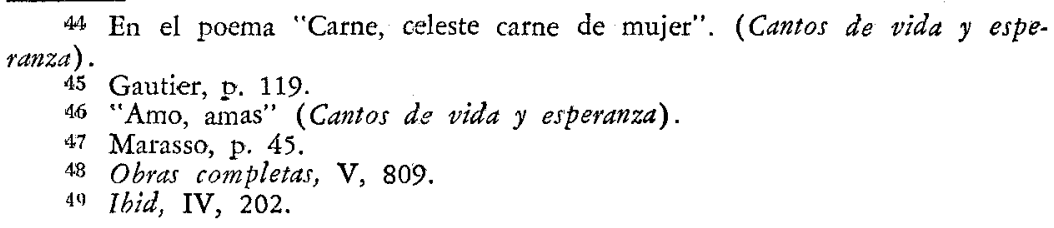
ranza).

44 En el poema "Carne, celeste carne de mujer". (Cantos de vida y espe-

45 Gautier, p. 119.

46 "Amo, amas" (Cantos do vida y esperanza).

47 Marasso, p. 45.

48 Obras completas, V, 809.

49 Ibid, IV, 202. 
"Chipre, Pafos, Tempes y Amatuntes", apunta "...con la excepción de Tempe, puesto allí como sitio delicioso", los demás son "lugares consagrados al culto de Venus".50 Sin embargo, Darío percibía una relación más íntima. Tempe no es, como sugiere Marasso, solamente un "sitio delicioso"; cabe en esta enumeración de localidades donde se celebraban los ritos de amor precisamente porque en Tempe tenían lugar los misterios de Dionysos. En Les grands initiés, libro que, según Marasso, Rubén leía continuamente, dice Edouard Schuré: "En Thessalie, dans le val enchanté de Tempé s'élève un temple mystique, fremé aux profanes. C'es là que Dionysos se manifeste aux mystes et aux voyants". 51

Nos parece evidente que para Darío el dios del vino y la diosa del amor se complementan. La primera "estampa" ¿qué es? ¿No vemos alli a Dionysos sobre la pantera ("las manchadas pieles de pantera") dirigiéndose tal vez hacia "la divina hoguera", seguido de bacantes? No nos debe sorprender la presencia de Baco: si Venus se acepta como diosa de la fertilidad, ¿por qué no admitir a Baco como digno compañero de la diosa? En las Geôrgicas ¿no invoca Virgilio al dios del vino?

\footnotetext{
Nunc te, Bacche, canam, nec non silvestria tecum

Virgulta et prolem tarde crescentis olivae.

Huc, pater o Lenaee; tuis hic omnia plena

Munerivus, tibi pampineo gravidus autumno

Floret ager, spumat plenis vindemia labris;

Huc, pater o Lenaee, veni, nudataque musto

Tingue novo mecum derettis crura coturnis.
}

(Lib. II)

Se sabe que Venus nos of rece su ambrosía ("mas dulce licor Venus escancia") y claro que en el poema de Darío también se halla el vino de Baco: ". . el rojo vino/conduce un paje rojo..." y viene después de recordar a Goethe, "... la uva teutona/el blanco vino...". Acaso Rubén hasta conociera lo que se dice en Pbilosophia secreld: "... por Baco se entiende el vino, y por Venus los deleites carnales. Estas dos cosas son las que mueven al ayuntamiento y deseo de los deleites, significados por Venus, y ardor interior, causado por el vino, el cual es Baco, porque el vino calentando las entrañas, nos mueve mucho a lujuria, y el atdor

50 Marasso, p. 46.

51 Édouard Schuré, Les grands initiés, (Paris, 1927), p. 237. Marasso se refiere a la lectura de Les grands initiés en Rubén Dario y sá creaciôn poética, p. 65 . 
causa el deseo...".52 Según la tradición clásica, Baco, así como Venus; tuvo muchos amores $y$ anduvo rodeado de satiresas.

Pero aparte lo que hemos aducido hasta aquí, ¿qué tiene que ver este dios con un poema en que se visitan diferentes países y continentes? ¿Será simplemente que Baco también anima toda la creación y que su influencia se siente por todo el mundo? ¿O habrá razones más específicas que relacionen a Baco con diversas culturas y civilizaciones? Hay que señalar que, según la tradición clásica, Baco, como el poeta en "Divagación", viaja por casi todo el mundo. En el Classical Dictionary de William Smith, leemos: ". .he wandered through various parts of the earth. He first went to Egypt, thence proceeded through Syria, then traversed all Asia... The most famous part of his wandering in Asia is his expedition to India...".53 ¿Sabría Darío de este aspecto de la leyenda de Baco? Nuestro poeta había estudiado la mitología tanto en la literatura clásica como en algunos libros sobre asuntos mitológicos; de modo que nadie se maravillará al leer en el ensayo sobre Ranvier: "No es el Baco triunfal que fue a la India, realzado en vasos y medallas..." 54 Rubén se había documentado bien, 55 por eso, al describir una bacanal en las primeras estrofas de su poema, sabe exactamente lo que quiere hacer. Las bacanales ¿qué son sino fiestas de amor, verdaderas Fêtes galantes, donde reina Baco? No cabe duda de que Baco, a su manera también, es dios del amor y que representa "the incarnate lifeforce itself, the uncontrollable chaotic eruption of nature in individuals and cities...".56

El ascendiente de Baco sobre Rubén quizá explique por qué "Verlaine es más que Sócrates; y Arsenio / Houssaye supera al viejo Anacreonte." En Los raros, hablando de Verlaine, Rubén confiesa que "t... despues de saber la fe sublime y el amor furioso y la inmensa poesía que tenían por habitáculo aquel claudicante cuerpo infeliz, sentí nacer en mi corazón un doloroso cariño ..."57 Ese hombre, ebrio de licor y de "amor furioso", tenía que constituir para Darío casi una reencarnación de Baco. ¿Y Arsenio Houssaye? ¿Cómo viene a colocarse al lado de Verlaine? Marasso no explica por qué Houssaye merece un lugar en el poema; por el contrario, parece sugerir que Darío se equivoca al mencionar a Arsenio Hous-

52 J. Pérez de Moya, I, 269-270.

53 William Smith, Classical Dictionary (London, 1876), p. 148.

is Obras completins, I, 627.

55 Todo el estudio de Marasso sobre Dario prueba que nuestro poeta se docuntentaba bien y que poseía una cultura considerable.

56 William Arrowsmith, en Euripides III (New York, 1959), p. 351.

57 Obras completas, II, 293. 
saye: "... la desemejanza entre las diosas de Clodion y las de Fidias no la encontró Arsenio, que, fuera de duda, prefería a Clodion, sino Henri Houssaye. . "58 Pero es que Darío introduce a Arsenio Houssaye en su poema porque posee algo que le recuerda a Baco. Darío dice: "Para él el universo era una fiesta sobre la cual estaba la sonrisa aprobadora del buen Dios. Supo de todos los amores, en su París, y para que nada quedara por desear, una de sus esposas fue limeña." 59 Si no hubiera sabido de todos los amores, ¿se le habría situado en el poema al lado de Verlaine? Claro que no. Es el parecido a Verlaine - y por ende, a Bacolo que atrae a Darío; Houssaye es "raro" como Verlaine y el bardo nicaragüense lo elogia: "Asi debía ser, joh viejo poeta y cronista del amor! tu entierro, una fiesta pagana y lírica, cantos de triunfo ... muchas flores, de manera que Carón no apareciese con su esquife, para tu alma, sino que ésta se embarcase en viaje a una Citeres ideal, en una barca como las que sabía construir tu amigo Banville, conducida por una tripulación escogida en los mejores tapices de Watteau." $60 \mathrm{Si}$ recordamos el "Responso a Verlaine" y el ensayo sobre el autor de Sagesse en Los raros, no se nos escapará la extraordinaria semejanza entre Verlaine y Houssaye.

¿Y qué diremos de los otros hombres que también figuran en el poema - Lohengrin, Goethe, Heine y Salomón? Todos sempiternamente enamorados, ¿no representan también ellos diversos avatares de Baco? $Y$ todos estos personajes masculinos se juntan con sus compañeras marquesas, campesinas, bailarinas y princesas para celebrar una gloriosa y sublime bacanal. Esta fiesta amorosa no nos debe escandalizar, puesto que en la unión de estos individuos se expresan las irresistibles fuerzas de la naturaleza que encarnan Venus y Baco. En verdad, como sostenía Rubén, los viejos dioses viven: " $\ldots$ es mentira que ha muerto ninguno de ellos... Los dioses no se han ido, los dioses no se van: cambian de forma y continúan animando el universo y aplicando su influencia sobre el hombre". ${ }^{61}$

\section{$\mathrm{V}$}

Deberíamos creerle a Rubén cuando nos dice en las "Palabras liminares" de Prosas profanas "Yo he dicho, en la misa rosa de mi juventud, mis antífonas, mis secuencias, mis profanas prosas."62 Efectiva-

58 Marasso, p. 47.

59 Obras completas, IV, 815.

6a Ibid., p. 816.

61 Ibid., I, 262.

62 Ibid,., V, 762 . 
mente, se trata de himnos a la esperanza, a la vida, al amor, himnos profanos pero himnos de donde no se excluye lo religioso. En la obra de un poeta muy admirado por Rubén - Laurent Tailhade- hay un poema, "Hymne antique", en que se canta a Venus "suivant le rit antique". Al escribir "Divagación", Darío debió pensar en este tipo de poesía que recuerda muy especialmente los epitalamios clásicos. La presencia de Venus y de Baco en el poema nos obliga a pensar en el himeneo, ¿no nos dice Pérez de Moya, "Himeneo, según Alberico, fue hijo de Baco y de Venus"? 63

Ese recurgo estilístico de Heredia ("Viens...") utilizado también por Chénier y Banville - poetas helenistas como el autor de Les trophées - se debe relacionar con los epitalamios clásicos. En uno de los más célebres, el Cantar de los cantares, se lee: "Ven conmigo del Líbano, esposa mía". ${ }^{44}$ Ya en "Primaveral", Dario había escrito:

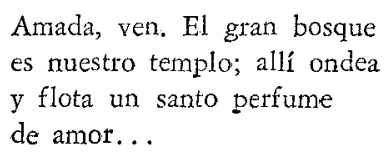

Si en "Divagación" Rubén implora a. Venus y a Baco, pidiéndoles que le sean propicios en su amoroso viaje mundial, es que no puede contener su desbordante voluptuosidad, sus ansias por lo inefable. En el Cantar de los cantares se reúnen el amor profano y el amor místico, y Darío quisiera penetrar también en el arcano misticismo que cree inherente en el amor. Si aceptamos lo que narra el nicaragüense ex "Tigre Hotel", ${ }^{5}$ el punto de partida de Rubén fue esta vez un sentimiento vago de ensueño - verdadera y maravillosa realidad poéticapero al darle forma en verso, acaso se dio cuenta de que no podría captar exactamente ese vaporoso ensueño. Entonces deja vagar su imaginación y el resultado es un poema que refleja su peculiar manera de concebir el amor. Su instinto erótico lo ha llevado impetuosamente hacia la, expresión de su anhelo por lo infinito, y Rubén entiende que sus poderosas inclinaciones eróticas no se encuentran en contradicción con su deseo de un amor que abarque todo, un amor total, cósmico, perfecto.

Salinas, al analizar "Divagación", señala que Darío se vale de una técnica dieciochesca, el uso del espejo: "Los espejos nos duplican, nos triplican, nos convierten en tantas imágenes como cristales azogados nos

63 Pbilosopbia secreta, I, 269.

64. IV, 8.

65 Obras completas, IV, 967-972. 
pongamos alrededor; esas imágenes a su vez se reflejan unas en otras. Y se llega a la multiplicación indefinida de nuestra simple unidad. Es el espejo un maestro del engaño visual. En ellos podemos ser muchos, variarnos en múltiples apariencias". ${ }^{66}$ Mediante estos engaños visuales -o verbales - Rubén intenta captar lo inmutable, lo eterno en contraste con lo circunstancial y aparencial. Hacia el final del poema, después de trasladarse al exótico oriente, se hacen más claramente patentes las intenciones de Darío. Su sensualidad desorbitante se transfigura de pronto al encontratse con "las pupilas llenas de visiones" de una japonesa y la "visión suprema de los mitos" del amor hindú. Cuando el poeta exclama extático, "Amame, así, fatal, cosmopolita...", ¿no aspira a una unión total, universal? En "Las palabras de la Satiresa", dice, "... que está el secreto de todo ritmo y pauta / en unir carne y alma a la esfera que gira". Se trata de una fusión cósmica completa, pero el pensamiento rubeniano, después de reducir todo al elemento primario, no puede menos que valerse de una imagen bíblica, conservando en el poema un leve sabor cristiano.

Rubén sabe que el hombre pertenece a la naturaleza, que es carne tanto como espíritu y que en muchas de las civilizaciones precristianas no existía escisión entre lo etótico y lo religioso. En "Divagación", de las culturas más recientes se evocan precisamente esas escenas en que aparecen personajes que encarnan algo de la espontaneidad amorosa de las culturas antiguas. No se estime una milagrosa coincidencia que en las únicas estrofas que se relacionan con el mundo cristiano de nuestros tiempos se recuerde solamente el erotismo místico del Cantair de los cantares. Es que la manera en que Darío concibe el amor se separa manifiestamente de lo que se entiende normalmente por misticismo cristiano. En el pensamiento de Rubén, no se puede oponer lo carnal a lo espiritual. Octavio Paz observa que la cosmología de Dario culmina en la expresión de un "misticismo etótico" 67 y que el poeta "no busca salvar su yo ni el de su amada sino confundirlos en el océano cósmico..." 68

Pero dígase lo que se diga, en "Divagación" Darío logró fijar su curiosa interpretación - frívola en apariencia- de lo que era para él una profunda y maravillosa realidad cosmológica. La poesía refleja no solamente esa aparente frivolidad - ¿por qué debería excluir lo frívolo?-

65 Salinas, 0. 131.

67 Octavio Paz, Cuadrivio (México, 1965), p. 57.

68 Ibit. Octavio $\mathrm{Paz}$ también relaciona el pensamiento de Dario con el taósmo: "Estas ideas, corrientes en la alquimia sexual del taósmo y en el tantrismo budista e hindú. nunca habian aparecido con tal violencia en la poesía castellana..." (Ibid.). 
sino también la cristalización de un concepto esotérico de la existencia. No se debe aceptar lo uno sin lo otro. A Darío parece interesarle más que la exaltación de un veleidoso instinto sexual, penetrar hasta el interior de lo que él considera lo más oculto, trascendental y eterno en el amor.

Darío cree que el poeta "tiene la visión directa e introspectiva de la vida y una supervisión que va más allá de lo que está sujeto a las leyes del general conocimiento. La religión y la filosofía se encuentran con el arte en tales fronteras..." 69 Ya en la época de $A z u l$ había querido expresar su estremecimiento ante "el enigma de la universal palpitación" ${ }^{70}$ y cuando escribe el "Coloquio de los centauros" exalta "la unidad del universo" creyendo firmemente que "hay tres cosas que dan testimonio en la tierra: el espíritu, el agua y la sangre y estos tres no son más que uno".71 No diremos que Darío logró todo lo que se propuso, pero sí que no hay por qué dudar de sus intenciones. Rubén nos dice que en "Amo, amas" pone "el secreto del vivir en el sacro incendio universal amoroso"72 y en "Divagación" ¿no acomete una empresa semejante?

\section{VI}

Ese "Vienes?" con que principia "Divagación", en nuestra opinión, nos revela algo de lo que se proponía Darío. Importante también nos parece la gran admiración que Rubén manifiesta abiertamente por la obra de Gautier, porque esa influencia nos suministra la clave de ciertos aspectos de la poesía. Las fuentes literarias estudiadas por Marasso nos ayudan a situar el poema dentro de lo que creemos sea su propia tradición literaria. Y de todo esto, se desprende que "Divagación" es una composición poética donde convergen reminiscencias de epitalamios, cantos a Baco y a Venus, viajes poéticos a Citeres, tratados profanos sobre el amor, libros ocultistas y poesía mística.

La presencia de Venus y de Baco en el poema evidencia también que Rubén acaso empleaba una técnica literaria parecida a la que describió Valle-Inclán. Este procedimiento consiste en ver "con ojos de altura para poder abarcar todo el conjunto y no los detalles mudables". ${ }^{73}$ Ade-

69 Obras completas, V, 955-956.

70 Ibid., p. 200.

71 Ibid., p. 209.

72 Ibid, p. 222.

73 Pedro Laín Entralgo, La generactón del noventa y ocho, 5a ed. (Madrid, 1963), p. 206. 
más, dice el autor de T'irano Banderas, "hay que pintar a las figuras añadiéndoles aquello que no hayan sido. Así un mendigo debe parecerse a Job y un guerrero a Aquiles" ${ }^{74} Y$ una amante a V|enkus, agregaría Rubén. En "Divagación" se muestran las diversas manifestaciones de Venus y de Baco, arquetípicas representaciones de las fuerzas naturales que animan la creación. Hay que penetrar hasta la intimidad del poema para darse cuenta que lo real para Rubén no puede ser lo exterior y estático, lo apariencial; la verdadera realidad arranca del espíritu dinámico ("The force that through the green fuse drives the flower", según Dylan Thomas) que refleja impulsos cósmicos. Por consiguiente, Darío no se preocupa por meras existencias circunstanciales; deriva hacia las manifestaciones literarias, hacia las interpretaciones más notables de los arquetipos de Venus y Baco.

No cabe duda que "Divagación", como afirma Marasso, es una "poesía sabia"."75 No se escribió apresuradamente, ni sin hacer algunos estudios preliminares. Darío mismo indica que durante los años que preparaba sus Prosas profanas, "no se comprendía el valor del estudio y de la aplicación constante, y se creía que con el solo esfuerzo del talento podría llevarse a cabo la labor emprendida".76 Pero a pesar de ese estudio y esa aplicación constante, la verdad es que no toda la crítica supo apreciar esas profanas prosas. En particular, parece que "Divagación" se juzgó uno de los poemas de menos sustancia. Sin embargo, si no se descubrió un fondo conceptual en la poesía, por lo menos no se desdeñó su forma exterior.

Absurdo sería culpar a Darío por la incomprensión de la crítica. Mucho más grave estimamos el hecho de que el poeta haya guardado silencio después de leer el comentario de Rodó. ¿Cómo pudo aceptar sin protesta un estudio que hacía hincapié únicamente en lo exterior del poema? Francisco Contreras opina que "Rubén Dario era amable hasta con sus detractores. Jamás censuraba $y$; ni cuando se trataba de ideas estéticas, llegaba a exaltarse". 77 En lo que se refiere a los juicios de Rodó, el caso es que no sólo ocultó Darío su disconformidad sino que aplaudió al maestro uruguayo. ¿Por qué? En "Dilucidaciones", recordando que Menéndez y Pelayo había afirmado que los versos de "Pórtico" eran "los viejos endecasílabos de gaita gallega", Rubén dice, "Y yo aprobé.

74 Ibid.

75 Marasso, p. 43.

76 Obras complesas, I, 205.

77 Francisço Contrẹras, Rubén Dario, Su vida y su obra (Barcelona, 1930), p. 83 . 
Porque siempre apruebo lo correcto, lo justo y lo bien intencionado". ${ }^{8}$ Así pues la crítica de Rodó, no obstante su insistencia en los aspectos formales de "Divagación", debió parecerle correcta y bien intencionada. A más de esto, Darío nunca negó su preocupación por la forma, aunque tampoco le concedió primacía en la creación poética. "La forma", sostiene el poeta, "es lo que primeramente toca a las muchedumbres. Yo no soy un poeta para la muchedumbre. Pero sé que indefectiblemente tengo que ir a ellos". ${ }^{79}$ Años después, sin embargo, nos pregunta: ". . ¿ ¿se trata, de una cuestión de formas? No. Se trata, ante todo, de una cuestión de ideas", $80 \mathrm{Y}$ asegura que "la palabra nace juntamente con la idea, o coexiste con la idea, pues no podemos darnos cuenta de la una sin la otra".81

Muy natural que Darío se sinticra frustrado y a veces cohibido ante lo que él llamaba la "inanidad de la crítica";82 pero consideraba ocioso enojarse. Ya mucho antes habia decidido no hacerle caso a celui-qui-necomprend-pas: ". . cierra los ojos y toca para los habitantes de tu reino interior", dice Rubén. "La gritería de trescientas ocas no te impedirá, silvano, tocar tu encantadora flauta..." ${ }^{83}$ Que ni siquiera se imaginara el alcance de algunas de sus poesías no parece haberle molestado sobremanera. Hasta muy probable es que lo considerara normal: "Siempre habrá poesía y siempre habrá poetas. Lo que siempre faltará será la abundancia de los comprendedores". ${ }^{84}$ En realidad, nunca esperó que toda su obra resultara claia y de fácil acceso: "...voy diciendo mi verso con una modestia tan orgullosa, que solamente las espigas comprenden". ${ }^{85}$ Algo de la incomprensión se puede atribuir a lo que Rubén entendía por poesía: "El don de arte es un don superior que permite entrar en lo desconocido de antes y en lo ignorado de después, en el ambiente del ensueño o de la meditación". ${ }^{86}$ De ahí que el verdadero sentido de parte de su obra pudiera escapátsele a muchos; pero Darío, siempre profesando una estética acrática, confiesa que afortunadamente existe una élite. "Yo digo la palabra que encarna mi pensamiento y mi sentimiento. La doy al mundo como Dios me la da. No busco que el Público me

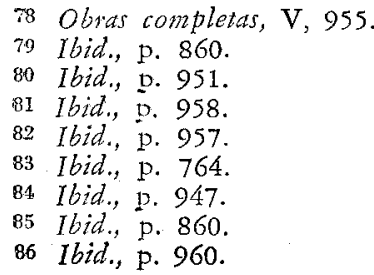


entienda. Quiero hablar para las orejas de los elegidos... A ellos mi ser, la música intencional de mi lengua... ". 87

Huelga decir que no podemos estar de acuerdo con Rodó. La mujer de "Divagación" es mucho más que "una francesa del siglo de los "duques-pastores" " y aunque "las exquisiteces del decir" y "las graciosas petulancias de las formas" nos parecen notables, no se debe admitir lo que Mapes aseguraba, que a Darío "peu lui importe le sujet". Tampoco se puede considerar "Divagación" simplemente "una clara definición de los motivos exteriores del modernismo", y mucho menos acertado nos parece el juicio de que en el poema Darío canta un amor "sin raíz y sin comprensión para más que la flor de la piel". Claro está que al poeta nicaragüense no se le puede relegar sumariamente a la categoría de poeta "carente de ideas". Darío poseía ideas, y también una curiosa y profunda percepción de nuestra existencia en el universo. El agudo poeta Valle-Inclán le confió a Francisco Contreras: "Rubén es un genio. Su observación no tiene nada que ver con la de los escritores comunes, como Blasco Ibáñez, por ejemplo. Êl percibe la relación misteriosa de las cosas...".88 Es evidente que en "Divagación", extraordinaria Carte du tendre cosmológica, Dario quiso aprehender algo de esa honda visión que señala Valle-Inclán y otro tanto de la exuberante exaltación de su gran espíritu erótico religioso.

State University of New York

\section{Alberto J. Carlos}

at Albany

87 Citado (p. XXXVI) por Alfonso Méndez Plancarte en la introducción a Sor Juana Inés de la Cruz, El sueño (México, 1951).

88 Contreras, op. cit., p. 104. 
